\title{
A Comparison of Learning Styles and Study Strategies Scores of Brunei Secondary School Students by Test Anxiety, Success Attributions, and Failure Attributions: Implications for Teaching At-risk and Vulnerable Students
}

\author{
Rohani Matzin ${ }^{1}$, Masitah Shahrill ${ }^{1}$, Salwa Mahalle ${ }^{1}$, Malai Hayati Sheikh Hamid ${ }^{1} \&$ Lawrence Mundia $^{1}$ \\ ${ }^{1}$ Sultan Hassanal Bolkiah Institute of Education, Universiti Brunei Darussalam, Jalan Tungku Link, Bandar Seri \\ Begawan, Brunei Darussalam \\ Correspondence: Rohani Matzin, Sultan Hassanal Bolkiah Institute of Education, Universiti Brunei Darussalam, \\ Jalan Tungku Link, Gadong BE 1410, Bandar Seri Begawan, Brunei Darussalam. Tel: 673-246-3001. E-mail: \\ rohani.matzin@ubd.edu.bn
}

Received: August 7, 2013 Accepted: September 16, 2013 Online Published: October 15, 2013

doi:10.5539/res.v5n5p119

URL: http://dx.doi.org/10.5539/res.v5n5p119

\begin{abstract}
The survey assessed the learning styles and study strategies of 135 randomly selected Brunei secondary school students according to their test anxiety levels, internal-external attributions for success, and internal-external attributions for failing. Four significant differences were obtained on learning styles but only one was found on study strategies. Highly anxious students scored higher on the social-individual learning style than their less anxious peers. Learners who internalize success attributions scored higher on the social-group learning style than counterparts who externalize. Participants with internal attributions for failing scored higher on both the visual-language and expressive-written learning styles than those who externalize reasons for failing. Paradoxically, females were the most affected by test anxiety and yet they outperformed males in mathematics achievement. We discuss plausible explanations for these findings and suggest psychological and educational interventions to address the observed deficiencies. Further mixed-methods research is recommended to gain additional insights into the issues investigated.
\end{abstract}

Keywords: learning styles, study strategies, test anxiety, internal-external attributions, mathematics achievement

\section{Introduction}

Prior to 1996, the Brunei education system was pretty examination-oriented (Mundia, 2010a). Adaptations to examinations and a reduction of dependence on examinations as a dominant mode for evaluating students were introduced with the implementation of inclusive education in 1997 (Mundia, 2010b). Further adaptations to examinations and reduction to dependence on examination-type assessments came in after the implementation of the ongoing SPN21 educational reforms (Mundia, 2010c).

Mathematics is one of the subjects that challenge Brunei secondary school students along with science and English. These three constitute key subjects used in the selection criteria of students for admission into Brunei tertiary institutions as well as for award of scholarships. Unfortunately, performance in mathematics is often poor particularly among male students. Coupled with this, in an educational system where student evaluations are frequent, it is quite possible that the assessments may produce a lot of tension, anxiety and stress in students. Recent past research efforts to know more about secondary students' mathematics problems have focused on a wide-range of issues other than test anxiety (that touch on mathematics in one way or the other) including the preparation of teachers to meet the challenges of inclusive education (Tait \& Mundia, 2012); comparison of Brunei pre-service student teachers' attitudes to inclusive education and specific disabilities (Haq \& Mundia, 2012); policy changes in Brunei teacher education (Mundia, 2012a); assessment of mathematics learning difficulties (Mundia, 2012b); overall improvement of university education including teacher programs (Mundia, 2012c); problems in learning mathematics (Mundia, 2010a); implementation of SPN21 curriculum (Mundia, 2010b); and implementation of inclusive education (Mundia, 2009). These studies have addressed a wide range of issues and problems related to teaching and learning in Brunei educational institutions. 


\section{Objectives of the Study}

The purpose of the present study was to determine the extent or degree to which secondary school students' scores differ on nine leaning style variables and six study strategy domains (by test anxiety, success attributions, failure attributions, math ability, and gender). Specifically, the study sought to determine the:

- differences in learning styles and study strategies by low and high scorers on test anxiety;

- differences in learning styles and study strategies by internal and external success attribution;

- differences in learning styles and study strategies by internal and external failure attributions; and

- differences in mathematics performance by test anxiety, success, and failure attributions.

The overall goal was to help identify areas needing psychological and educational interventions to help the students to improve achievement in mathematics.

\section{Method}

The study used field survey approach to investigate the problem. This research strategy differs from the telephone, online and postal survey techniques in that the researcher has to go into the fields (relevant educational institutions in the present study) to collect the data. The rationale and justification for employing this research strategy was two-fold. First, we wanted to involve as many secondary school students in the study as possible. Second, it was then possible to give on-the-spot assistance to respondents who needed help to complete the data collection instruments correctly thereby increasing the number of usable returns.

\section{Sample}

Participating schools and students were drawn randomly. Initially, a total of 157 questionnaires were distributed to chosen students but only 135 submitted properly completed and usable protocols. Of the remaining 22 , three did not return the questionnaires and were deemed as having declined to participate in the study while 19 were excluded from the study for endorsing item scales with central and extremity response biases including having many missing values. The participants' bio-data (gender, educational level, and age) are presented in Table 1.

Table 1. Demographic information $(\mathrm{N}=135)$

\begin{tabular}{lccc}
\hline Variable & Group & Frequency & Percentage \\
\hline Gender & Females & 77 & 57 \\
& Males & 58 & 43 \\
Education & Year 8 & 15 & 11 \\
& Year 9 & 59 & 44 \\
& Year 10 & 40 & 30 \\
Age & Year 11 & 21 & 15 \\
& & Mean & SD \\
& All & 14.650 & 1.088 \\
& Females & 14.650 & 1.121 \\
& Males & 14.660 & 1.052 \\
& Year 8 & 13.200 & 0.775 \\
& Year 9 & 14.370 & 0.945 \\
& Year 10 & 15.100 & 0.709 \\
& Year 11 & 15.620 & 0.865 \\
\hline
\end{tabular}

\section{Instruments}

We used three instruments to collect research data and these were: (1) the researcher-constructed demographical questionnaire that collected bio-data (gender, educational level and age) including internal-external attributions for success and failing; (2) the 4-point Likert-type Center for Innovative Teaching Experiences (CITE) Learning Styles Instrument comprising nine 5-item subscales (Babich, Burdine, Albright, \& Randol, 1976); (3) the 51-item College Level Study Skills Inventory (CLSSI) consisting of six subscales each with 5-point nominal rating values attached to the items (Congos, 2011); and (4) the 2002 revised edition of the Suinn Test Anxiety Behavior Scale, The STABS (Suinn, 1969) to measure test anxiety. 
The CITE Learning Styles Instrument (Burdine et al., 1976) is intended to help teachers to determine the learning styles preferred by their students. According to Burdine et al. (1976) it is divided into the following three main areas:

- Information gathering includes auditory language, visual language, auditory numerical, visual numerical, and auditory-visual language, auditory numerical, visual numerical, and auditory-visual-kinesthetic combination.

- Work conditions focus on whether a student works better alone or in a group.

- Expressiveness considers if a student is better at oral or written communication.

The adjusted total scores on the Learning Styles Inventory fall into one of three categories: major, minor, and negligible. Burdine et al. (1976) define these categories as follows in terms of the adjusted total scores:

- Major (33-40): The student prefers this mode of learning, feels comfortable with it, and uses it for important (to the student) learning. A student does not necessarily have one and only one preferred style.

- Minor (20-32): The student uses this mode but usually as a second choice or in conjunction with other learning styles.

- Negligible (05-19): The student prefers not to use this if other choices are available. The student does not feel comfortable with this style.

The CLSSI (Congos, 2011) is divided into the following 6 subscales: Text book reading (8 items); Note-taking (5); Memory (9); Test preparation (13); Concentration (10; and Time management (6). Each item is rated on a 5-point Likert-type scale ranging from $1=$ Almost never, through $3=$ About half of the time, to $5=$ Almost always. This questionnaire was found suitable for use with secondary school students in Brunei. Interpretations and meanings attached to subtest cut-off (criterion/critical) scores are as follows.

- Textbooks: less than a score of 30 suggests that changes in textbook reading skills are likely to increase grades.

- Note-taking: less than a score of 20 suggests that changes in note-taking skills are likely to increase grades.

- Memory: less than a score of 30 suggests that changes in memory skills are likely to increase grades.

- Test preparation: less than a score of 40 suggests that changes in test preparation skills are likely to increase grades.

- Concentration: less than a score of 35 suggests that changes in concentration skills are likely to increase grades.

- Time management: less than a score of 20 suggests that changes in time management skills are likely to increase grades.

The STABS (Suinn, 1969) is a 5-point Likert scale with 48 items. The instrument is not divided into subscales. In view of this total scores could range from 48-240. According to the scale's data processing instructions, students scoring 160 and above (coded 1 in this study for analysis purposes) were considered to have had problems with test anxiety while those scoring 48-159 (coded 2) had no problems with test anxiety. In the present study, The STABS had an alpha reliability of 0.0000 . Its correlation with the CITE learning styles subscales ranged from -0.009 to 0.226 (Mean $=0.033$ ). The correlations with the CLSSI study strategies questionnaire ranged from 0.116 to 0.211 (Mean $=0.121$ ).

We also collected the respondents' continuous assessment math grades for the previous academic term from school records. In predictions of academic success, previous research has used either grades or grade point averages (GPA) as measures of academic achievement or performance. Two illustrative examples here are Broussard (2002) who used grades as an indicator of academic achievement and Rickets (2003) who employed GPA as an index of academic performance. Although these grades were obtained from different assessment tasks, they were (regardless of the subject, educational level, and school) standardized in the whole Brunei education system (where $\mathrm{A}=80-100 \%$; $\mathrm{B}=70-79 \%$; $\mathrm{C}=60-69 \%$; $\mathrm{D}=50-59 \%$; $\mathrm{E}=40-49 \%$; and $\mathrm{F}=0-39 \%$ ). The distribution of math grades in the present study for all the 135 participants across the four levels of secondary education (Year 8 to Year 11) ranged from $A$ to $F$. The letter grades were then converted to their numerical equivalents (e.g. $\mathrm{A}=5 ; \mathrm{B}=4 ; \mathrm{C}=3 ; \mathrm{D}=2 ; \mathrm{E}=1$; and $\mathrm{F}=0$ ). Being sensitive data and for ethical reasons, the grades were analyzed and reported only at the group level. In the present study, high (top) math achievers were 
students who obtained A-B grades (coded 3 for analysis purposes) while low (bottom) achievers were those who got E-F grades (coded 1). The majority of the participating students scored in the middle of the range with C-D grades (coded 2). The descriptive statistics and reliability coefficients for the learning styles and study strategies subscales are presented in Table 2.

Table 2. Descriptive statistics and reliability of the instrument $(\mathrm{N}=135)$

\begin{tabular}{clccccc}
\hline \multicolumn{1}{c}{ Subscale } & Items & Mean & SE Mean & SD & Alpha \\
\hline \multirow{3}{*}{ Learning Styles } & & & & & \\
& Visual-Language & 5 & 14.660 & 0.187 & 2.172 & 0.792 \\
& Visual-Numerical & 5 & 14.730 & 0.207 & 2.407 & 0.653 \\
& Auditory-Language & 5 & 13.830 & 0.224 & 2.608 & 0.700 \\
& Auditory-Numerical & 5 & 14.210 & 0.230 & 2.672 & 0.840 \\
& Auditory-Visual-Kinesthetic & 5 & 15.160 & 0.174 & 2.027 & 0.695 \\
& Social-Individual & 5 & 15.190 & 0.229 & 2.658 & 0.793 \\
& Social-Group & 5 & 15.530 & 0.232 & 2.701 & 0.842 \\
& Expressiveness-Oral & 5 & 13.950 & 0.202 & 2.351 & 0.772 \\
& Expressiveness-Written & 5 & 13.930 & 0.204 & 2.371 & 0.819 \\
& & & & & & \\
Study Strategies & 8 & 25.590 & 0.420 & 4.884 & 0.677 \\
& Text book reading & 5 & 16.310 & 0.408 & 4.742 & 0.818 \\
& Note taking & 9 & 30.410 & 0.526 & 6.109 & 0.787 \\
& Memory & 13 & 41.830 & 0.560 & 6.504 & 0.821 \\
& Test preparation & 10 & 35.410 & 0.447 & 5.199 & 0.791 \\
& Concentration & 6 & 18.330 & 0.678 & 7.877 & 0.808 \\
\hline
\end{tabular}

The correlations in Table 3 may be interpreted in many ways. The low and non-significant correlations suggest that the scales are measures of different constructs and do not replicate each other. For these scales, the correlations provide good quantitative evidence for the scales' discriminant validity. The low but significant correlations imply that the scales (to a small extent) might be overlapping and measuring the same construct but the amount of duplication or common variance $\left(\mathrm{r}^{2}\right)$ is little and negligible. The paired scales can thus be said to have satisfactory discriminant validity and low convergence validity. The questionnaire scores and test grades used in the present study were considered to have had good ecological validity in that students obtained them in their respective schools. There was no evidence suggesting that students responded to questionnaire items cautiously and defensively. In addition, students obtained math test grades as part of continuous assessment. Such assessments exert less pressure, anxiety, tension, and stress to students compared to the abrasive demands of the final examinations.

Table 3. Convergence and discriminant validity of the instruments ( $\mathrm{N}=135)$

\begin{tabular}{|c|c|c|c|c|c|c|c|c|c|}
\hline Scales & Subscales & 1 & 2 & 3 & 4 & 5 & 6 & 7 & 8 \\
\hline \multirow[t]{9}{*}{ Learning Styles } & 1. Visual-Language & 1 & & & & & & & \\
\hline & 2. Visual-Numerical & $0.366^{* *}$ & 1 & & & & & & \\
\hline & 3. Auditory-Language & 0.083 & $0.203 *$ & 1 & & & & & \\
\hline & 4. Auditory-Numerical & 0.101 & $0.249 * *$ & $0.428 * *$ & 1 & & & & \\
\hline & 5. Auditory-Visual-Kinesthetic & $0.304 * *$ & $0.321 * *$ & $0.389 * *$ & $0.258 * *$ & 1 & & & \\
\hline & 6. Social-Individual & $0.331 * *$ & $0.259 * *$ & 0.083 & 0.161 & $0.219 *$ & 1 & & \\
\hline & 7. Social-Group & 0.119 & 0.156 & $0.384 * *$ & 0.055 & $0.246 * *$ & -0.086 & 1 & \\
\hline & 8. Expressiveness-Oral & $0.178 *$ & 0.116 & $0.177 *$ & 0.128 & 0.044 & $0.215^{* *}$ & 0.069 & 1 \\
\hline & 9. Expressiveness-Written & $0.404 * *$ & $0.361 * *$ & $0.272 * *$ & $0.264 * *$ & $0.395 * *$ & $0.308^{* *}$ & $0.355 * *$ & 0.026 \\
\hline \multirow{6}{*}{$\begin{array}{l}\text { Study } \\
\text { Strategies }\end{array}$} & 1. Text book reading & 1 & & & & & & & \\
\hline & 2. Note taking & $0.484 * *$ & 1 & & & & & & \\
\hline & Memory & $0.472 * *$ & $0.619 * *$ & 1 & & & & & \\
\hline & 4. Test preparation & $0.471 * *$ & $0.546 * *$ & $0.629 * *$ & 1 & & & & \\
\hline & 5. Concentration & $0.341 * *$ & $0.437 * *$ & $0.535 * *$ & $0.632 * *$ & 1 & & & \\
\hline & 6. Time management & $0.395 * *$ & $0.621 * *$ & $0.486 * *$ & $0.597 * *$ & $0.561 * *$ & & & \\
\hline$*$ & $\mathrm{p}<.05$ (2-tailed) & & & & & & & & \\
\hline$* *$ & $\mathrm{p}<.01$ (2-tailed) & & & & & & & & \\
\hline
\end{tabular}




\section{Data analysis}

The quantitative data were analyzed by both descriptive statistics (frequencies, percentages, mean and standard deviation) and inferential statistics (t-tests for independent samples incorporating ANCOVA F, and Pearson's correlations) and non-parametric statistics (chi-square). The rationale and justification for using these techniques is two-fold. First, the procedures were deemed to be appropriate for addressing the research objectives. Second, the data were obtained from a random sample and there was no evident violation of the statistical assumptions.

\section{Procedures}

Prior to collecting the data, the participants were told about the purpose and objectives of the study. No deception was involved in the study. In addition, the participants were told both verbally and in writing about the ethical conditions or requirements for being involved in the study. The discussion on this topic centered on issues of voluntary participation, privacy, anonymity, confidentiality, physical and psychological harm, debriefing, and informed consent. Students were given ample time to reflect on and withdraw from the study if they felt uncomfortable with the research's purpose and objectives. The participants voluntarily agreed to participate in the study. With regard to English language problems, the meanings of difficult English words, sentences and phrases on the instruments were verbally explained to the participants. Furthermore, students at the participants' university take most courses in English language and have participated in many research studies that required them to complete self-report scales/questionnaires in English. The researchers therefore deemed it not necessary to translate the instruments into Bahasa Melayu (Brunei's mother tongue and official language). The study met the ethical requirements for using human participants in research stipulated by the participants' university, the Government of Brunei, and the Helsinki Declaration.

\section{Results}

The findings of the study are presented below according to the four main objectives of the investigation.

\subsection{Differences in Learning Styles and Study Strategies by Low and High Scorers on Test Anxiety}

According to Table 4, high scorers on test anxiety tend to significantly use more of the social-individual learning style than low scorers. In addition, high scorers on test anxiety tend to significantly use more of the test preparation study strategy than low scorers. No other significant differences by test anxiety were obtained on the learning style and study strategies variables listed in Table 4.

Table 4. Means, standard deviations and T-values for low and high scorers on test anxiety $(\mathrm{N}=135)$

\begin{tabular}{lccccccc}
\hline \multirow{2}{*}{ Scale } & \multicolumn{2}{c}{$\begin{array}{c}\text { High scorers } \dagger \\
(\mathrm{n}=65)\end{array}$} & \multicolumn{2}{c}{$\begin{array}{c}\text { Low scorers } \dagger \\
(\mathrm{n}=70)\end{array}$} & ANCOVA & $\mathrm{T}$ & $\mathrm{P}$ \\
& Mean & SD & Mean & SD & $\mathrm{F}$ & $(d f=133)$ & $($ 2-tailed $)$ \\
\hline Visual-Language & 14.690 & 2.222 & 14.630 & 2.141 & 0.773 & 0.170 & 0.865 \\
Visual-Numerical & 14.820 & 2.364 & 14.660 & 2.461 & 0.321 & 0.380 & 0.704 \\
Auditory-Language & 13.970 & 2.750 & 13.700 & 2.481 & 0.000 & 10.598 & 0.551 \\
Auditory-Numerical & 14.380 & 2.854 & 14.060 & 2.502 & 0.105 & 0.710 & 0.479 \\
Auditory-Visual-Kinesthetic & 15.260 & 2.041 & 15.070 & 2.024 & 0.015 & 0.543 & 0.588 \\
Social-Individual & 15.660 & 2.683 & 14.760 & 2.579 & 0.278 & 1.997 & $0.048 *$ \\
Social-Group & 15.580 & 3.020 & 15.470 & 2.388 & 1.554 & 0.242 & 0.809 \\
Expressiveness-Oral & 14.150 & 2.438 & 13.760 & 2.268 & 0.113 & 0.979 & 0.329 \\
Expressiveness-Written & 13.850 & 2.306 & 14.000 & 2.444 & 0.207 & -0.375 & 0.708 \\
Text book reading & 25.980 & 5.054 & 25.210 & 4.727 & 0.013 & 0.915 & 0.362 \\
Note taking & 16.940 & 4.493 & 15.730 & 4.922 & 1.158 & 1.488 & 0.139 \\
Memory & 31.230 & 5.830 & 29.640 & 6.302 & 0.872 & 1.516 & 0.132 \\
Test preparation & 43.710 & 6.756 & 40.090 & 8.471 & $6.526 * *$ & 2.733 & $0.007 * *$ \\
Concentration & 36.450 & 5.879 & 34.460 & 6.940 & 1.564 & 1.790 & 0.076 \\
Time management & 19.110 & 4.910 & 17.600 & 5.380 & 0.627 & 1.695 & 0.092 \\
\hline
\end{tabular}

* $\quad \mathrm{p}<.05$ (2-tailed) $* * \quad \mathrm{P}<.01$ (2-tailed)

$\dagger \quad$ High scorers (scores $\geq 160$ ); Low scorers (scores $\leq 159)$

\subsection{Differences in Learning Styles and Study Strategies by Internal and External Success Attributions}

As indicated in Table 5, students who internalize success attributions scored significantly higher on the social-group learning style than peers who externalize success attributions. No other significant differences were 
found between students with internal and external attributions of success on all the other learning styles and study strategies variables presented in Table 5 .

Table 5. Means, standard deviations and T-values for internalizers and externalizers of success attributions $(\mathrm{N}=135)$

\begin{tabular}{lccccccc}
\hline \multirow{2}{*}{ Scale } & \multicolumn{2}{c}{ Internalizers $(\mathrm{n}=17)$} & \multicolumn{2}{c}{ Externalizers $(\mathrm{n}=118)$} & ANCOVA & $\mathrm{T}$ & $\mathrm{P}$ \\
& Mean & $\mathrm{SD}$ & Mean & $\mathrm{SD}$ & $\mathrm{F}$ & $(d f=133)$ & $(2$-tailed $)$ \\
\hline Visual-Language & 14.240 & 2.016 & 14.720 & 2.195 & 0.293 & -0.860 & 0.391 \\
Visual-Numerical & 15.350 & 2.422 & 14.640 & 2.402 & 0.246 & 1.136 & 0.258 \\
Auditory-Language & 14.410 & 3.203 & 13.750 & 2.516 & 1.864 & 0.984 & 0.327 \\
Auditory-Numerical & 14.240 & 2.773 & 14.210 & 2.669 & 0.201 & 0.034 & 0.973 \\
Auditory-Visual-Kinesthetic & 15.590 & 2.293 & 15.100 & 1.989 & 0.935 & 0.925 & 0.357 \\
Social-Individual & 14.820 & 2.651 & 15.250 & 2.666 & 0.021 & 0.611 & 0.542 \\
Social-Group & 16.760 & 2.137 & 15.350 & 2.734 & 0.913 & 2.046 & $0.043 *$ \\
Expressiveness-Oral & 13.670 & 2.359 & 13.970 & 2.359 & 0.211 & -1.343 & 0.732 \\
Expressiveness-Written & 14.060 & 1.886 & 13.910 & 2.439 & 1.062 & 0.246 & 0.806 \\
Text book reading & 26.000 & 5.244 & 25.530 & 4.851 & 0.006 & 0.373 & 0.709 \\
Note taking & 15.470 & 5.088 & 16.430 & 4.700 & 0.245 & -0781 & 0.436 \\
Memory & 32.060 & 6.823 & 30.170 & 5.993 & 0.131 & 1.194 & 0.235 \\
Test preparation & 42.940 & 8.807 & 41.670 & 7.763 & 0.011 & 0.621 & 0.536 \\
Concentration & 37.240 & 7.529 & 35.150 & 6.336 & 1.576 & 1.237 & 0.218 \\
Time management & 18.760 & 6.369 & 18.260 & 5.037 & 1.491 & 0.371 & 0.711 \\
\hline
\end{tabular}

$* \mathrm{p}<.05$ (2-tailed)

\subsection{Differences in Learning Styles and Study Strategies by Internal and External Failure Attributions}

Students who internalize failure attributions scored significantly higher on the visual-language and expressive-written learning styles (see Table 6). Internalizers and externalizers of failure attributions did not differ significantly on all the other variables shown in Table 6.

Table 6. Means, standard deviations and T-values for internalizers and externalizers of failure attributions $(\mathrm{N}=135)$

\begin{tabular}{lccccccc}
\hline \multirow{2}{*}{ Scale } & \multicolumn{2}{c}{$\begin{array}{c}\text { Internalizers } \\
(\mathrm{n}=84)\end{array}$} & \multicolumn{2}{c}{$\begin{array}{c}\text { Externalizers } \\
(\mathrm{n}=51)\end{array}$} & ANCOVA & $\mathrm{T}$ & $\mathrm{P}$ \\
\cline { 2 - 5 } & Mean & $\mathrm{SD}$ & Mean & $\mathrm{SD}$ & $\mathrm{F}$ & $(d f=133)$ & $(2$-tailed $)$ \\
\hline Visual-Language & 14.940 & 2.102 & 14.200 & 2.227 & 0.113 & 1.950 & $0.053^{*}$ \\
Visual-Numerical & 14.930 & 2.178 & 14.410 & 2.736 & $4.653 *$ & 1.212 & 0.228 \\
Auditory-Language & 13.860 & 2.694 & 13.780 & 2.484 & 0.268 & 0.157 & 0.876 \\
Auditory-Numerical & 14.050 & 2.697 & 14.490 & 2.633 & 0.037 & -0.933 & 0.353 \\
Auditory-Visual-Kinesthetic & 15.310 & 2.024 & 14.920 & 2.028 & 0.001 & 1.079 & 0.283 \\
Social-Individual & 14.430 & 2.475 & 14.800 & 2.919 & 1.0601 & 1.327 & 0.187 \\
Social-Group & 15.810 & 2.515 & 15.060 & 2.949 & 2.662 & 1.574 & 0.118 \\
Expressiveness-Oral & 13.870 & 2.301 & 14.080 & 2.448 & 0.741 & -0.500 & 0.618 \\
Expressiveness-Written & 14.300 & 2.453 & 13.310 & 2.112 & 0.055 & 2.378 & $0.019 *$ \\
Text book reading & 25.310 & 5.051 & 26.040 & 4.609 & 0.114 & -0841 & 0.402 \\
Note taking & 16.010 & 4.801 & 16.800 & 4.648 & 0.100 & -0.941 & 0.349 \\
Memory & 30.380 & 6.060 & 30.450 & 6.249 & 0.007 & -0.064 & 0.949 \\
Test preparation & 41.960 & 7.751 & 41.610 & 8.154 & 0.467 & 0.254 & 0.800 \\
Concentration & 35.730 & 6.325 & 34.900 & 6.821 & 0.453 & 0.713 & 0.477 \\
Time management & 18.460 & 4.895 & 18.100 & 5.707 & 1.551 & 0.396 & 0.693 \\
\hline
\end{tabular}

$* \mathrm{p}<.05$ (2-tailed)

$* * \mathrm{p}<.01$ (2-tailed) 


\subsection{Differences in Mathematics Performance by Test Anxiety, Success, and Failure Attributions}

Although the frequencies in Table 7 do not statistically differ significantly, it is evident that low scorers on test anxiety, externalizers of success, and internalizers of failure performed slightly better in mathematics than their counterparts. These results have practical significance discussed below.

Table 7. Participants' achievement in mathematics by test anxiety, success attributions and failure attributions $(\mathrm{N}=135)$

\begin{tabular}{|c|c|c|c|c|c|c|c|c|}
\hline \multirow[b]{2}{*}{ Dimension } & \multicolumn{5}{|c|}{ Performance level in Mathematics $\dagger$} & \multirow[b]{2}{*}{$d f$} & \multirow[b]{2}{*}{$P$} & \multirow[b]{2}{*}{ Eta } \\
\hline & Group & Bottom & Middle & Top & $\mathrm{X}^{2}$ & & & \\
\hline \multirow[t]{2}{*}{ Test anxiety } & High scorers ${ }^{a}$ & 24 & 28 & 13 & 0.600 & 2 & 0.741 & 0.067 \\
\hline & Low scorers ${ }^{a}$ & 27 & 26 & 17 & & & & \\
\hline \multirow{2}{*}{$\begin{array}{l}\text { Success } \\
\text { attributions }\end{array}$} & Internalizers & 3 & 8 & 6 & 3.824 & 2 & 0.148 & 0.168 \\
\hline & Externalizers & 48 & 46 & 24 & & & & \\
\hline \multirow{2}{*}{$\begin{array}{l}\text { Failure } \\
\text { attributions }\end{array}$} & Internalizers & 37 & 30 & 17 & 3.729 & 2 & 0.155 & 0.166 \\
\hline & Externalizers & 14 & 24 & 13 & & & & \\
\hline
\end{tabular}

$\dagger$ Bottom (Grades F, E); Middle (Grades D, C); Top (Grades B, A)

a High scorers (scores $\geq 160$ ); Low scorers (scores $\leq 159$ )

\subsection{Participants by Gender, Test Anxiety, Success Attributions, Failure Attributions, and Math Achievement}

Overall, Table 8 suggests that more females suffer from test anxiety than males. Despite this setback, females performed better in mathematics than males. The two genders do not differ significantly in the way they make attributions for either success or failure in mathematics.

Table 8 . Number of participants by gender, test anxiety, success attributions, failure attributions and math achievement $(\mathrm{N}=135)$

\begin{tabular}{lllllll}
\hline Dimension & Group & Females & Males & $\mathrm{X}^{2}(d f)$ & P (2-tailed $)$ & Eta \\
\hline Test anxiety & High scorers & 46 & 19 & $\begin{array}{l}9.647 \\
(1)\end{array}$ & $0.002 * *$ & 0.267 \\
& Low scorers & 31 & 39 & & & \\
Success attributions & Internalizers & 11 & 6 & 0.467 & 0.494 & 0.059 \\
& Externalizers & 66 & 52 & $(1)$ & & \\
Failure attributions & Internalizers & 53 & 31 & 3.330 & 0.068 & 0.157 \\
& Externalizers & 24 & 27 & $(1)$ & & \\
& Top & 19 & 11 & 8.626 & $0.012 * *$ & 0.197 \\
Math achievement & Middle & 37 & 17 & & & \\
& Bottom & 21 & 30 & & &
\end{tabular}

\section{Discussion}

The present study found high scorers on test anxiety tend to be more reliant on the social-individual learning style (Table 4). As introverts, their high test anxiety or worries might partly be due to lack of a learning buddy to ask when and where they do not know something. Note also from Table 4 that highly anxious students scored significantly on the test preparation study strategy. The problem here is that although they work hard to prepare 
for tests/exams, the quality of their preparation might be inferior thereby resulting in poor performance since test anxiety was not correlated with math achievement in this study. Because numerical grades were ordinal data, Spearman rank order correlations between math grades, test anxiety, success attributions and failure attributions in the present study were computed and all found to be low and non-significant as follows: math grades versus text anxiety $[\mathrm{r}(135)=0.013, \mathrm{p}>.05]$; math grades versus success attributions $[\mathrm{r}(135)=0.023, \mathrm{p}>.05]$; and math grades versus failure attributions $[\mathrm{r}(135)=-0.019, \mathrm{p}>.05]$. In addition, we observed from the present study that students who internalize success attributions scored higher on the social-group learning style (Table 5). It appears that cooperative learning (group work or collaboration) helps students to experience success individually and this ultimately enables them to boost their interest and intrinsic motivation. Furthermore, students with strong internal attributions for failing math, scored higher on the visual-language and expressive-written learning styles (Table 6). The reasons for these two findings are not clear from the present study but we suspected and speculated that these were students who learn better the concepts by reading written texts and by writing or constructing their own notes to remember things effectively. They therefore need assistance in the effective use of these learning styles. Moreover, based on the findings presented in Table 7, we formulated three interpretive hypotheses. First, low scorers on test anxiety apparently performed slightly better $(p>.05)$ than high scorers because they presumably experience less worries, tension, anxiety and stress. Second, students with strong external attributions for success performed a little better $(\mathrm{p}>.05)$ than the internalizers because externalizing success encourages and permits students to seek help from peers, teachers, parents, and a wide range of inanimate sources such as internet, television, and libraries. Third, the students who internalize attributions for failing math were not too bad in math compared to those who externalize (note: $p>.05$ ). The reason for this non-significant difference allegedly seems to be that internalizing failure allows students to take personal responsibility for the adverse outcome and this probably improves the learner's intrinsic motivation. Table 8 gives an overall picture and summarizes the connections between the variables investigated. A difficult-to-interpret paradoxical finding in this table is that females were the most affected by test anxiety and yet they outperformed males in mathematics performance or achievement. This suggests that not all anxiety is bad and perhaps an optimal amount/level of anxiety might be necessary to drive a learner to achieve a challenging goal of passing a feared subject such as mathematics.

\section{Conclusion}

Based on the findings from the present study, we conclude that coaching students in the effective use of learning styles and study strategies that are empirically proved by research to be useful might be beneficial in reducing test anxiety and raising math achievement among less able students of both genders. The learning styles that need to be addressed according to the results of this research are visual-language, expressive-written, social-individual, and social group. Babich et al (1976) provide detailed explanations of how CITE learning styles affect learners and how instruction could be to address learners' concerns and needs. With regard to study strategies, findings from this study suggest that highest attention and priority in psycho-educational interventions should be accorded to test preparation skills. Congos (2011) explains how the use of effective study skills could help students to achieve better in any subject.

\section{Limitations}

The present study was informed by three main limitations. First, as a survey the results cannot establish cause-and-effect relationships in the variables investigated. Second, a qualitative interview component is missing but was necessary to triangulate findings from the quantitative survey. Third, no attempt was made to obtain criterion-related validity of the scales used due to concerns that students were too busy with exam preparations towards the end of the school year and did not have a lot of time to complete many questionnaires at the time of data collection.

\section{References}

Babich, A. M., Burdine, P., Albright, L., \& Randal, P. I. (1976). Center for Innovative Teaching Experiences (CITE) Learning Styles Instrument. Wichita, KA: Murdoch Teachers Center.

Broussard, S. C. (2002). The relationship between classroom motivation and academic achievement in first and third graders. Master of Science (MS) Thesis. Agricultural and Mechanical College. Louisiana State University.

Congos, D. H. (2011). College Level Study Skills Inventory. Orlando, FL: University of Central Florida. 
Haq, F. S., \& Mundia, L. (2012). Comparison of Brunei pre-service student teachers' attitudes to inclusive education and specific disabilities: Implications for teacher education. Journal of Educational Research, 105(5). 366-374. http://dx.doi.org/10.1080/00220671.2011.627399

Mundia, L. (2009). Implementation of inclusive education in Brunei Darussalam: Review of possible implications on school counselors. Electronic Journal for Inclusive Education, 2(4). Retrieved from http://www.cehs.wright.edu/ prenick/Spring_Summer09_Edition/spr_sum09.html

Mundia, L. (2010a). Problems in learning mathematics: Comparison of Brunei junior high school students in classes with and without repeaters. Journal of Mathematics Research, 2(3), 150-160.

Mundia, L. (2010b). Implementation of SPN21 curriculum in Brunei Darussalam: A review of selected implications on school assessment reforms. International Education Studies, 3(2), 119-129.

Mundia, L. (2012a). Policy changes in Brunei teacher education: Implications for the selection of trainee teachers. The Education Forum, 76(3), 326-342. http://dx.doi.org/10.1080/00131725.2012.682489

Mundia, L. (2012b). The Assessment of Mathematics Learning Difficulties in a Primary Grade 4 Child with High Support Needs: Mixed Methods Approach. International Electronic Journal of Elementary Education, $4(2), 347-366$.

Mundia, L. (2012c). Assessment of GenNEXT learning outcomes at the University of Brunei Darussalam: A qualitative review of selected opportunities, benefits and challenges in human resource development. Journal of International Education and Leadership, 2(3).

Rickets, J. C. (2003). The efficacy of leadership development, critical thinking dispositionsand student academic performance on the critical thinking skills of selected youth leaders. Doctor of Philosophy (PhD) Dissertation. Graduate School. University of Florida.

Suinn, R. M. (1969). The STABS, a measure of test anxiety for behavior therapy: Normative data. Behavior Research and Therapy, 7, 335-339. http://dx.doi.org/10.1016/0005-7967(69)90018-7

Tait, K., \& Mundia, L. (2012). Preparing teachers to meet the challenges of inclusive education in Negara Brunei Darussalam. In C. I. Forlin (Ed.), Future directions for inclusive teacher education: An international perspective (pp. 60-69). Hong Kong: Routledge/Francis \& Taylor.

\section{Copyrights}

Copyright for this article is retained by the author(s), with first publication rights granted to the journal.

This is an open-access article distributed under the terms and conditions of the Creative Commons Attribution license (http://creativecommons.org/licenses/by/3.0/). 